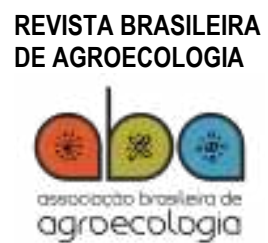

ISSN: $1980-9735$

DOI: $10.33240 /$ rba.v14i4.22923

\title{
EFICIÊNCIA DE MÉTODOS DE ESCARIFICAÇÃO NA SUPERAÇÃO DE DORMÊNCIA DE PELTOPHORUM DUBIUM(SPRENGEL) TAUBERT
}

\author{
Efficiency of scarification methods in overcoming dormancy of \\ Peltophorum dubium (Sprengel) Taubert
}

Kíva Soares de Oliveira ${ }^{1}$ e Magdi Ahmed Ibrahim Aloufa ${ }^{2}$

1 Doutoranda do Programa de PósGraduação em Desenvolvimento e Meio Ambiente, Universidade Federal do Rio Grande do Norte. E-mail: kiviaoliv@yahoo.com.br

2 Professor Adjunto do Departamento de Botânica e Zoologia, Universidade

Federal do Rio Grande do Norte. E-mail: magdialoufal@gmail.com

\section{Recebido em:}

24/02/2019

Aceito para publicação em:

10/10/2019

\section{Correspondência para:} kiviaoliv@yahoo.com.br

\section{RESUMO}

O objetivo deste trabalho foi avaliar os efeitos da escarificação mecânica e química na superação da dormência tegumentar de sementes de canafistula. Os tratamentos utilizados foram: testemunha (sementes intactas); imersão em álcool (46,6ㅇ) por 30 e 60 min.; imersão em ál$\operatorname{cool}(96,6$ ) $)$ por 30 e 60 min., lixa $n^{\circ} 60$ e desponte. Os métodos mais adequados para superar a dormência tegumentar das sementes de $P$. dubium são o desponte e escarificação mecânica com lixa $n^{\circ} 60$.

Palavras-chave: Caesalpinioideae. Dormência tegumentar. Escarificação mecânica.

\section{ABSTRACT}

The objective of this study was to evaluate the effects of mechanical and chemical scarification on the overcoming of canafistula seeds integumentary dormancy. The chosen treatments were: control (intact seeds); immersion in alcohol (46.6) for 30 and 60 minutes; immersion in alcohol (96.6\%) for 30 and 60 minutes, sandpaper $n^{\circ} 60$ and blunts. The most appropriate methods to overcome the integumentary dormancy of the $P$. dubium seeds are the pruning and mechanical scarification with sandpaper $n^{\circ} 60$.

Keywords: Caesalpinioideae. Integumentary dormancy. Mechanical scarification. 
O Brasil é um país rico em recursos genéticos, porém, espécies da flora nativa com grande potencial de uso estão se perdendo em virtude da intensificação da pressão antrópica sobre os recursos naturais e padrões culturais que dão preferência ao cultivo de espécies exóticas. Diante disso, ressaltase a necessidade de desenvolver estratégias que integrem sistemas de conservação da biodiversidade e desenvolvimento sustentável.

Nos últimos anos, a produção de mudas nativas tem sido destinada para atender aos processos de restauração ambiental (MUSSI et al., 2013). Para suprir a crescente demanda por produtos florestais madeireiros (PFM), com propriedades tecnológicas que atendam aos múltiplos usos, torna-se necessário promover pesquisas que aprimorem esse processo, propiciando baixo custo e boa qualidade, bem como maior potencial de sobrevivência e desenvolvimento após o plantio (BORTOLINI et al., 2012).

A canafistula (Peltophorum dubium (Sprengel) Taubert), Leguminosae da subfamília Caesalpinioideae, é uma espécie arbórea nativa do Brasil, com ampla distribuição geográfica. É muito explorada em função da qualidade da madeira, moderadamente pesada, dura e de longa durabilidade, de alto valor comercial e potencial no mercado madeireiro brasileiro (BERTOLINI et al., 2015). É considerada uma espécie multiuso, sendo bastante empregada para indústrias madeireiras, fabricação de móveis, construção civil, produção de lenha, energia, além de ser utilizada como planta ornamental e medicinal (REITZ et al., 1978). Possui potencial madeireiro e ecológico, com rápido crescimento, pouca exigência em fertilidade e umidade do solo, potencial fixadora de nitrogênio no solo, sendo amplamente utilizada na restauração de áreas degradadas (CARVALHO, 2003; SENEME et al., 2012). Em ambiente natural, sua germinação é dificultada pelo fato das sementes apresentarem dormência devido à impermeabilidade do tegumento (PEREIRA et al., 2013).

A dormência de sementes é um fenômeno que ocorre com frequência em muitas espécies florestais, sendo de grande importância em condições naturais por se constituir em estratégia de sobrevivência e perpetuação da espécie (SANTANA et al., 2011). Quando se visa à produção comercial de mudas, passa a ser um problema, sobretudo, pela desuniformidade e por aumentar o tempo de exposição às condições adversas, assim como os riscos de perda de sementes por deterioração (AZEREDO et al., 2010). Nesse aspecto, torna-se imperativa a realização de estudos sobre métodos práticos de superação da dormência, que aprimorem a germinação e o desempenho de mudas no viveiro, visando acelerar e uniformizar o estabelecimento inicial de plantas em condições de campo (SANTANA et al., 2011).

Em muitas espécies leguminosas como a canafistula, a dormência é devido à resistência e impermeabilidade do tegumento, que dificulta as trocas gasosas e o fluxo de água da semente com o meio externo, inviabilizando a uniformidade na emergência das sementes (GRUS, 1990). Dentre os métodos mais utilizados para acelerar e uniformizar a germinação destaca-se a escarificação mecânica e a química, que promovem a ruptura ou enfraquecimento do tegumento, permitindo a penetração da água, assim, dando início ao processo germinativo (MAYER e POLJAKOFF-MAYBER, 1989).

A escarificação manual ou mecânica é um dos métodos mais tradicionais e práticos no processo de quebra de dormência de sementes (SANTANA et al., 2011). É uma técnica simples, de baixo custo, a qual promove a rapidez e uniformidade da germinação (ABREU et al., 2017). Mostra-se muito eficaz para a superação da dormência de espécies florestais, em especial as leguminosas (FOWLER et al., 2000). Os processos mecânicos podem ser empregados mediante a utilização de lixas e tesouras (desponte ou corte no tegumento). Os químicos, por sua vez, pela ação de álcool sobre o tegumento, ambos tem a finalidade de balancear a entrada e saída de água e gases (POPINIGIS, 1985; OLIVEIRA et al., 2012). Porém, cada método tem suas vantagens e desvantagens, sendo importante considerar, também, o custo efetivo e sua praticidade de execução.

Nesse contexto, no presente trabalho, objetivou-se avaliar os efeitos da escarificação mecânica e química na superação da dormência tegumentar de sementes de canafistula.

O estudo foi conduzido em casa de vegetação junto ao Laboratório de Biotecnologia de Conservação de Espécies Nativas, do Departamento de Botânica e Zoologia da Universidade Federal do Rio Grande do Norte, situada a $5^{\circ} 50^{\prime} 31^{\prime \prime}$ de latitude $S$ e $35^{\circ} 12^{\prime} 7^{\prime \prime}$ de longitude $W$ e altitude média de $50 \mathrm{~m}$. As sementes foram cedidas pelo IBAMA, localizado no Município de Nísia Floresta/RN. Após a 
aquisição, foram armazenadas em recipiente de vidro e acondicionadas à temperatura ambiente até a realização do experimento.

Para o teste de escarificação química, os tratamentos utilizados foram: To-testemunha (sementes intactas); $T_{1}$ - imersão em álcool 46,60 por 30 min; $T_{2}$ - imersão em álcool 46,60 por 60 min; $T_{3}$ - imersão em álcool 96,6 por $30 \mathrm{~min}$; $T_{4}$ - imersão em álcool 96,60 por $60 \mathrm{~min}$. O delineamento experimental foi inteiramente casualizado, com cinco tratamentos e quatro repetições de 25 sementes. Os parâmetros avaliados foram: porcentagem de germinação (\%); índice velocidade de germinação (IVG) segundo Maguire (1962); e o tempo médio de germinação (TMG), calculado de acordo com a fórmula proposta por Labouriau (1983).

As sementes foram inoculadas em placas de petri, contendo folhas de papel filtro e umedecidas com água destilada diariamente (aprox. $2 \mathrm{~mL}$ de água/uma vez ao dia). Após a inoculação, os ensaios foram mantidos em sala de crescimento, com fatores controlados de temperatura $\left(25 \pm 2{ }^{\circ} \mathrm{C}\right)$, fotoperíodo de $16 \mathrm{~h}$, intensidade luminosa de $60 \mu \mathrm{mol} . \mathrm{m}^{-2} \mathrm{~s}^{-1}$ e umidade relativa próxima de $76 \%$. Durante 30 dias, contados a partir da data de inoculação, foi registrado o início da germinação com a emissão da radícula.

Para a instalação do teste de escarificação física, a semeadura foi realizada em bandejas de isopor, contendo 100 células e colocada em casa vegetação, coberta com telado $(50 \%$ de sombreamento), em uma área experimental da Universidade Federal do Rio Grande do Norte, em Natal-RN, situada a 5०50'31" latitude sul e 3512'7' longitude Oeste.

As sementes permaneceram durante 30 dias em regime de rega diária (aprox. $10 \mathrm{~mL}$ de água/umavezaodia). Os tratamentos utilizados foram: $T_{0}$-testemunha; $\mathrm{T}_{1}$-escarificação manual com lixa $\mathrm{n}^{\circ} 60$ até o desgaste visível do tegumento do lado oposto ao hilo e $\mathrm{T}_{2}$ - desponte com auxílio de tesoura, mediante pequeno corte no tegumento na região oposta ao hilo, em substrato vermiculita, com quatro repetições de 25 sementes por tratamento.

Para avaliação da emergência total de plântulas e do índice de velocidade de emergência (IVE), foi feita a contagem diária das plântulas que emergiram até o momento de sua estabilização, iniciandose as verificações no primeiro dia após a semeadura (DAS) e encerrando-as no 290 dia. As variáveis avaliadas foram: porcentagem de emergência (\%); índice velocidade de emergência (IVE), segundo Maguire (1962); e tempo médio de emergência (TME), conforme Labouriau (1983).

Os dados foram submetidos ao teste de Shapiro-Wilk, para a normalidade dos resíduos, e de Levene para a homogeneidade entre as variâncias. Atendidas a essas duas pressuposições da estatística paramétrica, aplicou-se a análise de variância (ANOVA), seguida do teste de Tukey a $5 \%$ de probabilidade para comparações entre as médias, pelo software ASSISTAT versão 7.6 beta. Os dados em porcentagem de emergência foram transformados em arco-seno $x / 100$ para a obtenção da homogeneidade das variâncias e da normalização de sua distribuição. Na Tabela 1 são apresentadas as médias originais.

Houve efeito significativo dos tratamentos pré-germinativos para todas as variáveis analisadas, exceto para a porcentagem de germinação (Tabela 1).

Tabela 1. Valores médios de porcentagem de germinação, índice de velocidade de germinação e tempo médio de germinação de sementes de $P$. dubium, submetidas a diferentes tratamentos pré-germinativos.

\begin{tabular}{lccc}
\multicolumn{1}{c}{ Tratamento } & Germinação (\%) & IVG & TMG (dias) \\
\hline $\mathrm{T}_{0}$ - Testemunha & $20^{\mathrm{ns}}$ & $0,35 \mathrm{~b} *$ & $20,18 \mathrm{a}$ \\
$\mathrm{T}_{1}$ - Imersão em álcool 46,6o por $30 \mathrm{~min}$. & 34 & $1,43 \mathrm{a}$ & $13,48 \mathrm{~b}$ \\
$\mathrm{~T}_{2}$ - Imersão em álcool 46,6 por $60 \mathrm{~min}$ & 27 & $0,71 \mathrm{ab}$ & $21,17 \mathrm{a}$ \\
$\mathrm{T}_{3}$ - Imersão em álcool 96,6o por $30 \mathrm{~min}$ & 28 & $0,91 \mathrm{ab}$ & $17,24 \mathrm{ab}$ \\
$\mathrm{T}_{4}$ - Imersão em álcool 96,6o por $60 \mathrm{~min}$ & 40 & $1,28 \mathrm{ab}$ & $17,76 \mathrm{ab}$ \\
\hline $\mathrm{CV}$ (\%) & 19,57 & 21,82 & 7,80 \\
\hline
\end{tabular}

NS Não significativo. * Dados seguidos de mesma letra na coluna não diferem entre si estatisticamente ao nível de $5 \%$ de significância pelo teste de Tukey. 
A imersão em álcool 46,6 e 96,60, durante 30 e 60 minutos, não apresentou efeito sobre a germinação das sementes, uma vez que foram iguais à testemunha, com médias de sementes dormentes acima de $60 \%$ na maioria dos tratamentos. Ponce et al. (2017), também verificaram que a imersão em álcool $(92,8 \%)$ durante 30 e 60 minutos não foram eficientes na quebra de dormência das sementes de Canavalia gladiata (Jacq.) DC (Fabaceae), já que nesses tratamentos foram observadas maiores taxas de sementes dormentes ao final do teste de germinação.

A baixa eficiência da escarificação química através da imersão em álcool 46,60 e 96,60 pode estar associada ao tempo de imersão de 30 e 60 minutos que, possivelmente, foi insuficiente para o completo rompimento do tegumento das sementes. Logo, a alteração da permeabilidade do tegumento não foi o suficiente para promover a entrada de água e facilitar a protrusão da raiz primária (PONCE et al., 2017).

Os resultados de porcentagem de germinação, deste estudo, foram inferiores aos encontrados por Dutra et al. (2010) que, em estudos com sementes de macambira, obtiveram germinação acima de $75 \%$, utilizando álcool $70 \%$ por 30 e $60 \mathrm{~min}$. Smiderle et al. (2010), ao estudarem a quebra de dormência com sementes de Bauhinia angulata Vell (Fabaceae), verificaram que a utilização de álcool (10 e 15 min.) proporcionou germinação superior a 80\% em comparação ao ácido sulfúrico. Conforme os autores, 15 minutos foram o suficiente para promover germinação superior a $80 \%$, valor considerável se comparado à testemunha, que aos 89 dias germinaram apenas $19,4 \%$.

A utilização de álcool possibilita o aumento da permeabilidade na casca de várias espécies (MAYER e POLAKOFF-MAYBER, 1989). Por ser um solvente orgânico, o efeito benéfico se da no tegumento, permitindo a retirada de ceras e compostos graxos presentes na superfície ou na camada de células abaixo da cutícula, facilitando a germinação (SCALON et al., 2003). Apesar dos resultados não terem sido satisfatórios para quebrar a dormência de sementes de canafístula, já que a taxa de germinação obtida foi inferior a 50\%, ressalta-se que a vantagem do álcool reside na facilidade de aplicação, podendo ser usado para uma grande quantidade de sementes e seus resíduos serem reaproveitados em outras práticas.

Em relação ao TMG e IVG (Tabela 1), a imersão em álcool 46,60 por 30 minutos foi superior, seguido de T4, T3 e T2, diminuindo o tempo médio de germinação das sementes e aumentando sua uniformidade e vigor. Eller et al. (2010), em estudos com Caesalpinia ferrea, verificaram que a escarificação química utilizando álcool aumentou o tempo de germinação das sementes. Os autores justificam que pode ter ocorrido algum dano ao embrião, já que as sementes ficaram embebidas em álcool por dez horas, além disso, o método não se mostrou viável, pois retardou o processo germinativo e as plântulas acabaram morrendo após seu desenvolvimento. Já Scalon et al. (2003), verificaram que as sementes de sibipiruna ( $C$. pelthophoroides), tratadas com álcool e semeadas em terra adubada, apresentaram maiores taxas de germinação e IVG.

Dentre as diferentes concentrações e tempo de imersão no álcool, o T1 (Imersão em álcool 46,60 por 30min.) apresentou os melhores resultados de IVG e TMG, embora não tenha apresentado influência significativa na taxa de germinação. Ponce et al. (2017) relataram que as sementes de $C$. gladiata expostas a diferentes tratamentos pré-germinativos apresentam comportamentos distintos quanto à germinação e vigor, porém, nem sempre resultaram em plântulas vigorosas. Isso sugere que, embora alguns métodos sejam eficientes para promover a germinação, também podem reduzir o vigor, fato que não é desejado para a produção de mudas.

Quanto ao teste de escarificação física, houve efeito significativo dos tratamentos prégerminativos para todas as variáveis analisadas (Tabela 2). 
Tabela 2. Valores médios de porcentagem de emergência, índice de velocidade de emergência e tempo médio de emergência de plântulas de $P$. dubium, cujas sementes foram submetidas a tratamentos pré-germinativos.

\begin{tabular}{lccc}
\hline \multicolumn{1}{c}{ Tratamento } & Emergência (\%) & IVE & TME (dias) \\
\hline $\mathrm{T}_{0}$ - Testemunha & $41 \mathrm{~b}$ & $1,5 \mathrm{~b}$ & $15,57 \mathrm{a}$ \\
$\mathrm{T}_{1}$ - Lixada & $77 \mathrm{a}$ & $5,17 \mathrm{a}$ & $8,74 \mathrm{~b}$ \\
$\mathrm{~T}_{2}$ - Cortada & $82 \mathrm{a}$ & $5,44 \mathrm{a}$ & $8,19 \mathrm{~b}$ \\
\hline $\mathrm{CV}(\%)$ & 5.20 & 7.15 & 11.31 \\
\hline
\end{tabular}

* Dados seguidos de mesma letra na coluna não diferem entre si estatisticamente ao nível de $5 \%$ de significância pelo teste de Tukey.

As taxas de emergência para os tratamentos de escarificação mecânica com lixa $n^{\circ} 60$ (77\%) e desponte $(82 \%)$ diferiram, significativamente, da testemunha, a qual apresentou apenas $41 \%$ de emergência, e $59 \%$ de sementes dormentes. Piroli et al. (2005) constataram que a escarificação mecânica com lixa $\mathrm{n}^{\circ} 60$ promoveu o melhor resultado na superação de dormência da mesma espécie, com $89 \%$ de germinação. Porém, ressaltam que, apesar de eficiente na quebra de dormência, é um método bastante trabalhoso e demorado, já que a escarificação manual inviabiliza sua aplicação em larga escala. Abreu et al. (2017) verificaram que o melhor tratamento na quebra de dormência de Tachigali vulgaris foi o desponte do tegumento na região oposta ao hilo, com $91 \%$ de sementes germinadas. Em contrapartida, Alves et al. (2007), ao estudarem a quebra de dormência em sementes de catingueira (Caesalpinioideae), verificaram que o desponte obteve o pior resultado quando comparado à imersão em ácido sulfúrico por 8 e 10 minutos, escarificação manual com lixa e imersão em água a 80 ํC por 1 minuto.

Pode-se considerar o percentual de sementes germinadas amplamente favorável à utilização desse processo de escarificação mecênica. A lixa e o desponte são eficientes para romper o tegumento das sementes de $P$. dubium, por acelerarem o processo de embebição, culminando em maior rapidez na emergência das plântulas. Porém, deve-se atentar para os possíveis danos aos cotilédones, já que a utilização de material abrasivo requer cuidados quanto à intensidade e à forma de aplicação, para não comprometer a estrutura das sementes (MEDEIROS FILHO et al., 2002). Ressalta-se que se a escarificação for feita na região oposta ao hilo, a absorção de água ocorre sem causar tais danos (COELHO et al., 2010).

Os tratamentos pré-germinativos reduziram, significativamente, o tempo médio de emergência das sementes (Tabela 2). Os resultados diferem dos encontrados por Melo e Rodolfo Júnior (2006) que, em estudos com a mesma espécie, obtiveram menor tempo de emergência para a testemunha $(15,67$ dias), quando comparada à escarificação mecânica com lixa (20,02 dias). Para a espécie $B$. divaricata, em estudo realizado por Alves et al. (2004), os melhores tratamentos para superação de dormência foram o desponte (pequeno corte na região oposta à micrópila) e a escarificação mecânica.

Esses resultados podem ser justificados pelo fato da escarificação mecânica promover a entrada de água nas sementes e, consequentemente, a reativação dos processos metabólicos (KOBORI et al., 2013). Nesse aspecto, além de aumentar a permeabilidade à água, a retirada do tegumento possibilita maior sensibilidade à luz e à temperatura, remove inibidores ou promotores da germinação, influenciando, assim, no metabolismo e dormência das sementes (LOPES et al., 2006).

De modo geral, o desponte e a lixa promoveram melhores TME e IVE, confirmando a eficiência dos tratamentos para a superação da dormência de sementes $P$. dubium (Tabela 2). As sementes com maior vigor, avaliado pelo IVE, promovem estabelecimento rápido e uniforme das amostras, enquanto as sementes intactas atrasaram o início do processo germinativo.

A escarificação mecânica, através do uso da lixa $n^{\circ} 60$ e desponte, promoveram elevadas porcentagens de emergência $(77 \%$ e $82 \%)$ e maiores IVE $(5,17$ e 5,44$)$, respectivamente. Piroli et al. (2005) verificaram que a escarificação mecânica com lixa $n^{\circ} 60$ em sementes da mesma espécie foi o método que apresentou o melhor IVG. Pereira et al. (2011) constataram que a escarificação mecânica com lixa e desponte em sementes de Schizolobium parahyba mostraram-se mais eficientes para a germinação, IVG e TME, quando comparadas às técnicas de escarificação química com ácido sulfúrico e acido clorídrico. Já Oliveira et al. (2012), em estudos com a espécie Samanea tubulosa (Leguminoseae), constataram maior IVE utilizando o desponte. 
A eficiência da escarificação mecânica pode estar relacionada ao fato da mesma promover fissuras no tegumento, alterando a permeabilidade das sementes, assim, permitindo a embebição e consequente ativação do processo germinativo (MEDEIROS FILHO et al., 2002). A eficiência desses métodos também foi relatada em diversas espécies florestais, como em $B$. divaricata L. (ALVES et al., 2004), Parkia discolor (PEREIRA e FERREIRA, 2010), Piptadenia stipulacea (FARIAS et al., 2013), T. vulgaris (ABREU et al., 2017) e Delonix regia Rafin (OLIVEIRA et al., 2018).

O menor IVE nas sementes sem tratamento pré-germinativo, resultou em maior TME. Esses resultados confirmam a ocorrência de dormência tegumentar nas sementes de canafístula, pois seu percentual de emergência, ao final dos 30 dias, foi de apenas $41 \%$, índice 2,0 vezes menor que o da média dos demais tratamentos. Resultados semelhantes foram observados por Dutra et al. (2013), ao avaliarem diferentes métodos de quebra de dormência para a mesma espécie; porém, os valores de IVE, obtidos por esses autores, foram superiores aos obtidos neste trabalho.

Conforme Santana et al. (2011), o IVE reflete o comportamento temporal dos efeitos dos tratamentos na germinação das sementes e tende a atingir valores mais elevados quando o número de sementes germinadas nos primeiros dias do experimento é alto, contribuindo para melhorar a uniformidade da germinação e reduzir os custos de produção comercial das mudas.

Vale salientar que, os tratamentos de escarificação com lixa e desponte são métodos práticos, rápidos e de grande facilidade para o agricultor, que pode fazer uso em sua propriedade, com ferramentas de fácil obtenção. Desse modo, evitando o uso de produtos químicos tóxicos, que necessitem de manuseio cuidadoso e que gerem danos ambientais (KOBORI et al., 2013).

Os tratamentos pré-germinativos para superação de dormência das sementes de canafistula reduzem o tempo de germinação e emergência das plântulas. Porém, a dormência tegumentar das sementes de $P$. dubium por ser superada, de forma mais eficiente, pelos métodos de desponte e escarificação mecânica com lixa $\mathrm{n}^{\circ} 60$. Estes se mostraram simples, de baixo custo e eficiente, atingindo níveis de emergência similares aos de outros tratamentos já testados para superação de dormência.

\section{Referências}

ABREU, D. C. A.; et al. Métodos de superação da dormência e substratos para germinação de sementes de Tachigali vulgaris L.G. Silva \& H. C. Lima. Floresta e Ambiente, Rio de Janeiro, v. 24, p. 2-10, 2017.

ALVES, A. U. et al. Superação da dormência em sementes de Bauhinia divaricata L. Acta botânica brasílica, Belo Horizonte- MG, v. 18, n. 4, p. 871-879, 2004.

ALVES, E. U. et al. Superação da dormência em sementes de Caesalpinia pyramidalis Tul. Revista Árvore, ViçosaMG, v.31, n.3, p.405-415, 2007.

AZEREDO, G. A. et al. Superação de dormência de sementes de (Piptadenia moniliformis Benth). Revista Brasileira de Sementes, Londrina, v. 32, p. 49-58, 2010.

BERTOLINI, í. C.; et al. Caracterização silvicultural da canafístula (Peltophorum dubium (Sprengel) Taubert). Scientia Agraria Paranaensis, Marechal Cândido Rondon, v. 14, n. 2, p. 67-76, 2015.

BORTOLINI, M. F. et al. Crescimento de mudas de Gleditschia amorphoides Taub. produzidas em diferentes substratos. Ciência Florestal, Santa Maria, v. 22, n. 1, p. 35-46, 2012.

CARVALHO, P. E. R. Espécies arbóreas brasileiras. Colombo: EMBRAPA Florestas, v. 1, 2003. 1039 p.

COELHO, M. F. B. et al. Superação da dormência tegumentar em sementes de Caesalpinia férrea Mart ex Tul. Revista Brasileira de Ciências Agrárias, Recife, v. 5, n. 1, p. 74-79, 2010.

DUTRA, A. S.; et al. Germinação de sementes de macambira (Bromelia laciniosa Mart. ex S-chult). Revista Caatinga, Mossoró, v. 23, n. 2, p. 12-17, 2010.

DUTRA, T. R. et al. Substratos alternativos e métodos de quebra de dormência para produção de mudas de canafistula. Revista Ceres, Viçosa, v. 60, n.1, p. 072-078, 2013.

ELLER, E. et al. Efetividade de métodos de escarificação para quebra de dormência em sementes de Pau-Ferro (Caesalpinia férrea Mart). In: XIV Encontro Latino Americano de Iniciação Científica e X Encontro Latino Americano de Pós-Graduação, Universidade do Vale do Paraíba, 2010. p. 1-4.

FARIAS, R. M. et al. Superação de dormência em sementes de jurema-branca (Piptadenia stipulacea). Amazonian Journal of Agricultural and Environmental Sciences, Belém-PA, v. 56, n. 2, p. 160-165, 2013.

FOWLER, A. J. P.; BIANCHETTI, A. Dormência em sementes florestais. Colombo: Embrapa Florestas, 2000. 27p. (Embrapa Florestas. Documentos, 40). 
GRUS, V. M. Germinação de sementes de Pau ferro e Cassia javanesa submetidas a tratamentos para quebra de dormência. Revista Brasileira de Sementes, Londrina- PR, v. 2, n. 6, p. 29-35, 1990.

KOBORI, N. N.; MASCARIN, G. M.; CICERO, S. M. Métodos não sulfúricos para superação de dormência de sementes de mucuna-preta (Mucuna aterrima). Informativo ABRATES, Londrina-PR, v.23, n.1, 2013.

LABOURIAU, L. G. A germinação das sementes. Washington: OEA, 1983. 174p.

LOPES, J. C.; et al. Tratamentos para acelerar a germinação e reduzir a deterioração das sementes de Ormosia nitida Vog. Revista Árvore, Viçosa-MG, v. 30, n. 2, p. 171-177, 2006.

MAGUIRE, J. D. Speeds of germination-aid selection and evaluation for seedling emergence and vigor. Crop Science, Madison, v.2, p.176-177, 1962.

MAYER, A. M.; POLJAKOFF-MAYBER, A. The germination of seeds. $4^{\mathrm{a}}$ ed., New York: Pergamon Press, 1989. 270p.

MEDEIROS FILHO, S.; et al. Germinação de sementes de Operculina macrocarpa (L.) Farwel e Operculina alata (Ham.) Urban. Revista Brasileira de Sementes, Londrina-PR, v. 24, n. 2, p. 102-107, 2002.

MELO, R. R.; RODOLFO JÚNIOR, F. R. Superação de dormência em sementes e desenvolvimento inicial de canafístula (Cassia grandis L. f.). Revista Científica Eletrônica de Engenharia Florestal, ano IV, n· 7, 2006.

MUSSI, N. S. et al. Substratos orgânicos na produção de mudas de canafistula. Cadernos de Agroecologia, v. 8, n. 2, 2013.

OLIVEIRA, L. M. et al. Tratamentos pré-germinativos em sementes de Samanea tubulosa Bentham - (Leguminoseae- Mimosoideae). Revista Árvore, Viçosa-MG, v. 36, n. 3, p. 433-440, 2012.

OLIVEIRA, K. J. B. Quebra de dormência de sementes de Delonix regia (Fabaceae). Revista de Ciências Agrárias, Lisboa, v. 41, n. 3, p. 709-716, 2018.

PEREIRA, S. A.; FERREIRA, S. A. N. Superação da dormência em sementes de visqueiro-do-igapó (Parkia discolor). Acta Amazônica, Manaus-AM, v. 40, n. 1, p. 151-156, 2010.

PEREIRA, M. de O. et al. Avaliação de métodos de escarificação na superação de dormência de Schizolobium parahyba (Vell.) Blake (Fabaceae: Caesalpinioideae). Revista em Agronegócios e Meio Ambiente, Maringá-PR, v. 4, n. 1, p. 119-129, 2011.

PEREIRA, S. R. et al. Influência da temperatura na germinação de sementes de Peltophorum dubium (Spreng.) Taub. Informativo Abrates, Londrina-PR, v. 23, n. 3, p. 52-55, 2013.

PIROLI, E. L. et al. Germinação de sementes de canafístula Peltophorum dubium (Spreng.) Taub. tratadas para superação da dormência. Colloquium Agrariae, São Paulo, v. 1, n. 1, p. 13-18 13, 2005.

PONCE, R. M. et al. Quebra de dormência em sementes de Canavalia gladiata (Jacq.) DC. Rev. de Ciências Agrárias, Lisboa, v. 40, n. 4, 2017.

POPINIGIS, F. Fisiologia da semente. 2. ed. Brasília, DF: ABRATES, 1985. 298p.

REITZ, R.; KLEIN, R. M.; REIS, A. Projeto Madeira de Santa Catarina. Itajaí: Herbário Barbosa Rodrigues, 1978. 320p. SANTANA, J. A. da S. et al. Tecnologias de baixo custo para superação de dormência em sementes de Caesalpinia ferrea var. ferrea Mart. ex. Tul. (Pau Ferro). Revista Verde, Mossoró-RN, v. 6, n.1, p. 225-229, 2011.

SCALON, S. P. Q. et al. Efeito do álcool e substrato na germinação de sementes de sibipiruna (Caesalpinia pelthophoroides Benth.) colhidas no chão e retiradas da vagem. Ciênc. agrotec., Lavras,v. 27, n. 2, 2003.

SENEME, A. M. et al. Germinação, qualidade sanitária e armazenamento de sementes de canafístula (Peltophorum dubium). Revista Árvore, Viçosa-MG, v. 36, n.1, p. 01-06, 2012.

SMIDERLE, O. J.; LUZ, F. J. de F. Superação da dormência em sementes de pata-de-vaca (Bauhinia angulata Vell). Revista Agro@mbiente, Boa Vista-RR, v. 4, n. 2, p. 80-85, 2010. 